Check for updates

Cite this: RSC Adv., 2019, 9, 28078

\title{
Synthesis and characterization of a novel ruthenium(II) trisbipyridine complex magnetic nanocomposite for the selective oxidation of phenols
}

\author{
Zhengxin Fei, ${ }^{\text {ab }}$ Feng Chen, ${ }^{a}$ Mingqiang Zhong, ${ }^{a}$ Jianping Qiu, ${ }^{b}$ Weidong Li $\mathbb{D}$ *c \\ and Seyed Mohsen Sadeghzadeh (iD) de
}

Anchoring ruthenium(॥) trisbipyridine complex $\left[\mathrm{Ru}(\mathrm{Bpy})_{3}\right]^{2+}$ into a magnetic dendritic fibrous silica nanostructure produces an unprecedented strong nanocatalyst, $\mathrm{FeNi}_{3} / \mathrm{DFNS} /\left[\mathrm{Ru}(\mathrm{Bpy})_{3}\right]^{2+}$. Impressive oxidation of phenols to 1,4-benzoquinones catalyzed by $\mathrm{FeNi}_{3} / \mathrm{DFNS} /\left[\mathrm{Ru}(\mathrm{Bpy})_{3}\right]^{2+}$ is obtained in acetonitrile and water solution with molecular dioxygen as oxidant. Exclusively, apparently inert phenols such as phenol itself and mono-alkyl-substituted phenols are impressively oxidized to produce 1,4benzoquinones through activation of the $\mathrm{C}-\mathrm{H}$ bond in the position para to the carbon-oxygen bond under mild conditions. In addition, the production of industrially significant quinones that are known intermediates for vitamin combinations is investigated and studied FeNiz/DFNS/[Ru(Bpy) $]_{3}^{2+}$ magnetic nanoparticles were produced, and their properties were investigated by AFM, FTIR, XRD, TGA, SEM, TEM, and VSM.

Received 4th July 2019

Accepted 14th August 2019

DOI: $10.1039 / \mathrm{c} 9 \mathrm{ra0} 05079 \mathrm{e}$

rsc.li/rsc-advances

functionalized metal oxides and polymers as well as antioxi-

\section{Introduction}

Recently, the use of surfactant on soft template has led to the production of mesoporous silica with dendritic silica fiber morphology (DFNS). Silicas possessing this morphology are being tested experimentally as support materials for catalysis and adsorption processes. The outward radial widening of these silicas provides higher surface area for reactants to access the functional materials more efficiently. In addition to that, DFNS has intrinsic mesoporous properties, is thermally stable and exhibits high activity. The synthesis of DFNS requires a microemulsion system that contains surfactant, oil and water. Furthermore, the particle size and morphology of DFNS can be easily manipulated by introducing co-surfactant and various cosolvents. ${ }^{1-7}$

The alloy $\mathrm{FeNi}_{3}$ is magnetic and is utilized for its high permeability, low energy losses, high temperature and high saturation magnetism. Nevertheless, this nano adsorbent is subject to rusting and so researchers commonly utilize

${ }^{a}$ College of Material Science and Engineering, Zhejiang University of Technology, Hangzhou 310014, China

bJinhua Polytechnic, Jinhua 321007, China

'Polytechnic Institute of Qianjiang College, Hangzhou Normal University, Hangzhou, 310018, China.E-mail: lwd@hznu.edu.cn

${ }^{d}$ New Materials Technology and Processing Research Center, Department of Chemistry, Neyshabur Branch, Islamic Azad University, Neyshabur, Iran

${ }^{e}$ Young Researchers and Elite Club, Neyshabur Branch, Islamic Azad University, Neyshabur, Iran dants. The coating of $\mathrm{SiO}_{2}$ with $\mathrm{FeNi}_{3}$ nanoparticles may impressively enhance the electrical contact of materials in highfrequency applications. Currently, distinct approaches are utilized for providing nanocomposites of magnetic alloys and their nanoparticles. Nevertheless, in most cases, they need excessive as well as inappropriate conditions such as vacuum, inert atmosphere and sometimes hydrogen, high pressure and temperature. Moreover, studying the risks associated with $\mathrm{Fe}$ nanoparticles is a priority. ${ }^{8-14}$

Recently, half-sandwich complexes of organoruthenium have been much studied because of their catalytic and pharmacological characteristics. ${ }^{15,16}$ Their reactivity, biological activity $^{17,18}$ and also their catalytic activity may possibly be modified using appropriate ligand selection..$^{19-21}$ Loading them onto macromolecular systems such as dendrimers, metallocages, liposomes, and nanoparticles equipped $\mathrm{Ru}($ arene) and other metal complexes with the capacity to target tumors. ${ }^{22}$ By using catalysts on macromolecular supports, problems such as separation of catalyst from the obtained products, and recycling of the catalyst may be solved, ${ }^{23}$ as was observed in the study by Süss-Fink et al., which was performed for $\mathrm{Ru} /$ superparamagnetic iron oxide nanoparticles (SPIONs), ${ }^{24}$ as well as that by Fan and colleagues relating to $\mathrm{Ru}($ arene) organometallics. ${ }^{25}$ Moreover, such enhancement opens up opportunities in this field such as molecular nanomagnet development and also single molecule magnet preparation..$^{26,27}$ 
The selective oxidation of phenols is of major significance for the production of 1,4-benzoquinones, main intermediates for the production of vitamins $\mathrm{E}$ and $\mathrm{K}$. Different oxidant/ catalyst combinations like $\mathrm{O}_{2}$ or $\mathrm{H}_{2} \mathrm{O}_{2} / \mathrm{CuCl}_{2}$, particularly with different co-catalysts, are chosen in this oxidation approach. Nevertheless, the basic difficulty of this approach is that the use of homogeneous catalysts causes issues concerning separation and recycling of the catalyst as well as purification of products. Therefore, the development of more impressive as well as "green" catalysts for the selective oxidation is currently a big challenge. ${ }^{28-32}$

In previous studies, some teams showed that the $\mathrm{C}-\mathrm{H}$ bond reactivity of phenols in the para-position varied according to the substituents on the benzene ring. ${ }^{33,34}$ Commonly, when the number of alkyl groups is higher than 3 , the $\mathrm{C}-\mathrm{H}$ bond of these phenols has amplified reactivity. ${ }^{34}$ The method for oxidation of phenols to 1,4-benzoquinones is relatively straightforward. Multi-alkyl-1,4-benzoquinones are particularly reactive and side-reactions can be occur under oxidation conditions, but the $\mathrm{C}-\mathrm{H}$ bond in the para-position of phenol and in monoalkyl-substituted phenols is generally inert. Few methods are impressive under mild conditions. Moreover, 1,4-benzoquinone as well as mono-alkyl-1,4-benzoquinones are commonly more active than phenol and mono-alkyl substituted phenols; therefore, over-oxidation generally leads to reduced selectivity. However, it is desirable to develop effective catalysts for the optimized activation of the $\mathrm{C}-\mathrm{H}$ bond in the para-position of inert phenols towards dioxygen. The synthesis of quinones that are considered intermediates in the production of vitamins is of popular concern in organic industry. ${ }^{35-38}$ The selective oxidation of appropriate arenes to their respective quinones is the basic synthetic stage in the production of vitamin $\mathrm{K} 3$ (menadione) and 2,3,5-trimethylbenzoquinone (TMBQ), an intermediate for producing vitamin $\mathrm{E}$, as shown in Scheme 1. Both of the aforementioned vitamins are important food additives, and are produced on a several thousand-ton scale yearly. Moreover, oxidation of arenes to quinones is of biological significance, ${ }^{39-41}$ in photosynthesis as well as in the respiratory chain.

In the present study, a $\mathrm{Ru}(\mathrm{II})$ trisbipyridine complex is introduced into the fiber core of DFNS and used in the oxidation of phenols and production of vitamin K3. This new material has high hydrothermal stability, high surface area, and large pore<smiles>CC1=CC(=O)C(C)=C(C)C1=O</smiles>

2,3,5-trimethyl-benzoquinone

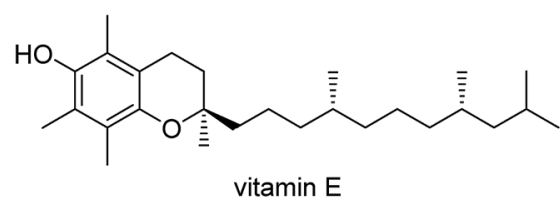

volume. In addition, it shows dramatically greater catalytic activity as well as a greatly enhanced lifetime in comparison with amorphous $\mathrm{SiO}_{2}$ in the selective oxidation of phenols to 1,4-benzoquinones under moderate conditions, as seen in Scheme 2.

\section{Experimental}

\section{Materials and methods}

High purity chemicals were procured from Fluka and Merck. 2,3,6-Trimethylphenol (95\%), 2,3,5-trimethylphenol (99\%), 3,5-dimethylphenol (>99\%), 2,6-dimethylphenol (99\%), 2methylphenol (>99\%), 3-methylphenol (99\%), 2-methoxyphenol (98\%), 2-tert-butylphenol (99\%), 2-fluorophenol (98\%), 2-chlorophenol (>99\%) and 2-iodophenol (98\%) were obtained from Merck. The Electrothermal 9100 apparatus was utilized for the determination of uncorrected melting points in open capillaries. A VERTEC 70 spectrometer (Bruker) in transmission mode was used for the determination of Fouriertransform infrared (FTIR) spectra. Samples were pulverized and pelleted with spectroscopic grade $\mathrm{KBr}$. Determination of size and structure of nanoparticles was done using transmission electron microscopy (TEM; Phillips CM10) operated at $100 \mathrm{kV}$. The crystallographic structures of nanoparticles were determined using powder X-ray diffraction (Bruker D8 Advance model) with $\mathrm{Cu} \mathrm{k} \alpha$ radiation. Thermal gravimetry analysis (TGA) (NETZSCH STA449F3) was utilized under nitrogen atmosphere with a heating rate of $10{ }^{\circ} \mathrm{C} \mathrm{min}{ }^{-1} \cdot{ }^{1} \mathrm{H}$ and ${ }^{13} \mathrm{C}$ NMR spectra were determined with a Bruker DRX-300 AVANCE spectrometer and a Bruker DRX-400 AVANCE spectrometer. The NMR spectra for the two elements were recorded at 300.13 and $75.46 \mathrm{MHz}$, and 400.22 and $100.63 \mathrm{MHz}$, respectively. A Heraeus CHN-O-Rapid analyzer was used to perform elemental analyses for carbon, hydrogen and nitrogen. Thin-layer chromatography (TLC) was performed on silica gel polygramSILG/UV 254 plates and used for the determination of product purity and for monitoring reactions. A Shimadzu GCMS-QP5050 mass spectrometer was used to record the mass spectra.

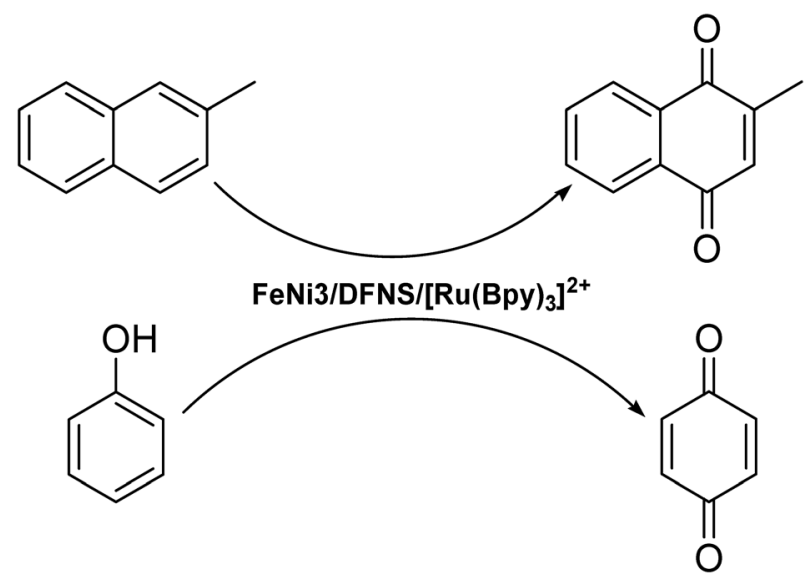

Scheme 2 Oxidation of phenols and 2-methylnaphthalene. 


\section{Total approach for the synthesis of $\mathrm{FeNi}_{3} \mathrm{MNPs}$}

The procedure for the preparation of $\mathrm{FeNi}_{3}$ magnetic nanoparticles (MNPs) involved dissolving $0.01 \mathrm{~mol} \mathrm{FeCl}_{2} \cdot 4 \mathrm{H}_{2} \mathrm{O}$ and $0.03 \mathrm{~mol} \mathrm{NiCl}_{2} \cdot 6 \mathrm{H}_{2} \mathrm{O}$ in $300 \mathrm{~mL}$ of distilled water and the subsequent addition of $1.0 \mathrm{~g}$ of polyethylene glycol (PEG, MW 6000). To achieve the $\mathrm{pH}$ range of $12 \leq \mathrm{pH} \leq 13$, sodium hydroxide $(\mathrm{NaOH})$ was added to the solution. Next, hydrazine hydrate $\left(\mathrm{N}_{2} \mathrm{H}_{4} \cdot \mathrm{H}_{2} \mathrm{O}\right)$ at $80 \%$ concentration was added to the suspension in varied quantity. The suspension was left to react continuously for $24 \mathrm{~h}$ at room temperature. The $\mathrm{pH}$ of the suspension was maintained at $12 \leq \mathrm{pH} \leq 13$ with periodic dosing of $\mathrm{NaOH}$. After that, the solid phase of the resultant mixture was filtered out to obtain black $\mathrm{FeNi}_{3}$ MNPs and rinsed with ionized water multiple times. ${ }^{42}$

\section{Total approach for the synthesis of $\mathrm{FeNi}_{3} / \mathrm{SiO}_{2} \mathrm{MNPs}$}

An aqueous solution containing $80 \mathrm{~mL}$ of ethanol, $20 \mathrm{~mL}$ of deionized water and $2.0 \mathrm{~mL}$ of $28 \mathrm{wt} \%$ concentrated ammonia aqueous solution $\left(\mathrm{NH}_{3} \cdot \mathrm{H}_{2} \mathrm{O}\right)$ was prepared. $\mathrm{FeNi}_{3}$ MNPs $(0.02$ $\mathrm{mol}$ ) were dispersed in the mixture and $0.20 \mathrm{~g}$ of tetraethyl orthosilicate (TEOS) was added subsequently. The mixture was vigorously stirred for $24 \mathrm{~h}$. The solid phase of the resultant mixture was filtered off and washed several times before being dried in atmospheric conditions at $60{ }^{\circ} \mathrm{C} .{ }^{42}$

\section{Total approach for the synthesis of $\mathrm{FeNi}_{3} / \mathrm{DFNS}$ MNPs}

Solution A was prepared as $30 \mathrm{~mL}$ of aqueous solution containing $0.3 \mathrm{~g}$ urea and a dispersion of $0.25 \mathrm{~g}$ of $\mathrm{FeNi}_{3} / \mathrm{SiO}_{2}$. The mixture was placed in an ultrasonic bath for $1 \mathrm{~h}$. Solution B was prepared by adding $0.5 \mathrm{~g}$ cetylpyridinium bromide (CPB) into $0.75 \mathrm{~mL}$ of $n$-pentanol and $30 \mathrm{~mL}$ of cyclohexane. Solution A and solution B were mixed and stirred at room temperature, and $1.25 \mathrm{~g}$ TEOS was added in a dropwise manner. The mixture was continuously stirred for $1 \mathrm{~h}$ at room temperature and placed in an oven at $120{ }^{\circ} \mathrm{C}$ for $5 \mathrm{~h}$ to incite reaction. The completed reaction was cooled to room temperature before applying strong magnetic force for the isolation of $\mathrm{FeNi}_{3} / \mathrm{DFNS}$ core-shell microspheres. The solid phase was then washed several times with water and acetone. The washed solid was dried in a drying oven at $40{ }^{\circ} \mathrm{C}$ overnight and calcined at $550{ }^{\circ} \mathrm{C}$ for $5 \mathrm{~h}$ in atmospheric conditions. ${ }^{42}$

\section{Total approach for the synthesis of $\mathrm{FeNi}_{3} / \mathrm{DFNS} / 3$ -} bromopropyl MNPs

$\mathrm{FeNi}_{3} /$ DFNS (200 mg) was mixed via ultrasonication with $20 \mathrm{~mL}$ of THF followed by the addition of $20 \mathrm{mmol}$ of $\mathrm{NaOH}$. After that, $22 \mathrm{mmol}$ of 3-bromopropyl trimethoxysilane was added into the mixture at room temperature and stirred for $16 \mathrm{~h}$ at $50{ }^{\circ} \mathrm{C}$. The resultant mixture was filtered and washed with ethanol and deionized water. The filtered solids were then dried under vacuum at $50{ }^{\circ} \mathrm{C}$ for $3 \mathrm{~h}$.

\section{Total approach for the synthesis of $\mathrm{FeNi}_{3} / \mathrm{DFNS} / \mathrm{Bpy}$ MNPs}

$\mathrm{FeNi}_{3} / \mathrm{DFNS} / 3$-bromopropyl (200 $\mathrm{mg}$ ) was diffused into a solution $(80 \mathrm{~mL})$ of ethanol, deionized water $(20 \mathrm{~mL})$ and $28 \mathrm{wt} \%$ concentrated aqueous ammonia $\left(\mathrm{NH}_{3} \cdot \mathrm{H}_{2} \mathrm{O}, 2.0 \mathrm{~mL}\right)$ and finally $20 \mathrm{mmol}$ of $2,2^{\prime}$-bipyridinyl-4, $4^{\prime}$-diol was added. After intense stirring, the suspension produced was filtered and washed repeatedly several times, and then dried at a temperature of $50{ }^{\circ} \mathrm{C}$ in the presence of air.

\section{Total approach for the synthesis of $\mathrm{FeNi}_{3} / \mathrm{DFNS} /\left[\mathrm{Ru}(\mathrm{Bpy})_{3}\right]^{2+}$ MNPs}

$3.0 \mathrm{mg}$ of $\mathrm{RuCl}_{3} \cdot 3 \mathrm{H}_{2} \mathrm{O}$ and $70 \mathrm{mg}$ of $\mathrm{FeNi}_{3} / \mathrm{DFNS} / \mathrm{Bpy}(0.041$ mmol) were dissolved into a wet DMF/EtOH $4 / 1(10 \mathrm{~mL})$ solution and the reaction mixture was heated to $70{ }^{\circ} \mathrm{C}$ for 72 hours. The reaction mixture was cooled to room temperature and concentrated under vacuum. The residue was dissolved in $\mathrm{CH}_{2} \mathrm{Cl}_{2}$ and also washed with distilled water. A saturated solution of $10 \mathrm{~mL} \mathrm{NH} \mathrm{NF}_{6}$ was added and the solid obtained was separated out by using an external magnet. After that it was dried under vacuum.

\section{Total approach for oxidation of phenol}

The selected phenol $(1 \mathrm{mmol})$ and $10 \mathrm{mg}$ of $\mathrm{FeNi}_{3} / \mathrm{DFNS} /$ $\left[\mathrm{Ru}(\mathrm{Bpy})_{3}\right]^{2+}$ MNPs in $10 \mathrm{~mL}$ of acetonitrile/water $100 / 8(\mathrm{v} / \mathrm{v})$ were placed in a flask which was then charged with pure oxygen at a pressure of $2 \mathrm{MPa}$. The mixture obtained was stirred at a temperature of $40{ }^{\circ} \mathrm{C}$ for 1 hour. The solution was diluted with ethyl acetate after the reaction was complete. The catalyst was separated out using an external magnet. The obtained solution was dried using sodium sulfate. Then, the excess solvent was removed under reduced pressure to provide the respective 1,4-benzoquinone. The substrate conversions and product yields were quantified by gas chromatography (GC) using biphenyl as the internal standard. Each experiment was reproduced at least three times. The experimental error in the determination of the substrate conversions and product yields normally did not exceed $2 \%$.

\section{Total approach for the synthesis vitamin K3}

2-Methyl naphthalene (10 mmol) compound, $2 \mathrm{~mL}$ glacial acetic acid, and $0.1 \mathrm{~mL} \mathrm{H}_{2} \mathrm{O}_{2}$ as well as $1 \mathrm{mg} \mathrm{FeNi} / \mathrm{DFNS}_{3} /\left[\mathrm{Ru}(\mathrm{Bpy})_{3}\right]^{2+}$ MNPs were stirred while being heated under reflux in $20 \mathrm{~mL}$ acetonitrile for around 8 hours. The catalyst was separated out using an external magnet. Solvent evaporation of the filtrate at decreased pressure provided the crude product. Vitamin K3 was isolated using GC on silica gel, eluted with petroleum ether/ EtOAc $(3: 1)$.

\section{Results and discussion}

In the present work, magnetic DFNS solution was produced according to reported methods and reacted with 3-bromopropyl trimethoxysilane, followed by reductive amination to make the corresponding co-immobilized $\left[\mathrm{Ru}(\mathrm{Bpy})_{3}\right]^{2+}$. This process can be observed in Scheme 3.

The morphology and the physical structure of $\mathrm{FeNi}_{3} / \mathrm{DFNS}$ and $\mathrm{FeNi}_{3} / \mathrm{DFNS} /\left[\mathrm{Ru}(\mathrm{Bpy})_{3}\right]^{2+}$ MNPs were analysed with fieldemission scanning electron microscopy (FESEM) and TEM (Fig. 1). As shown in Fig. $1 \mathrm{a}$ and c, the $\mathrm{FeNi}_{3} /$ DFNS possesses 


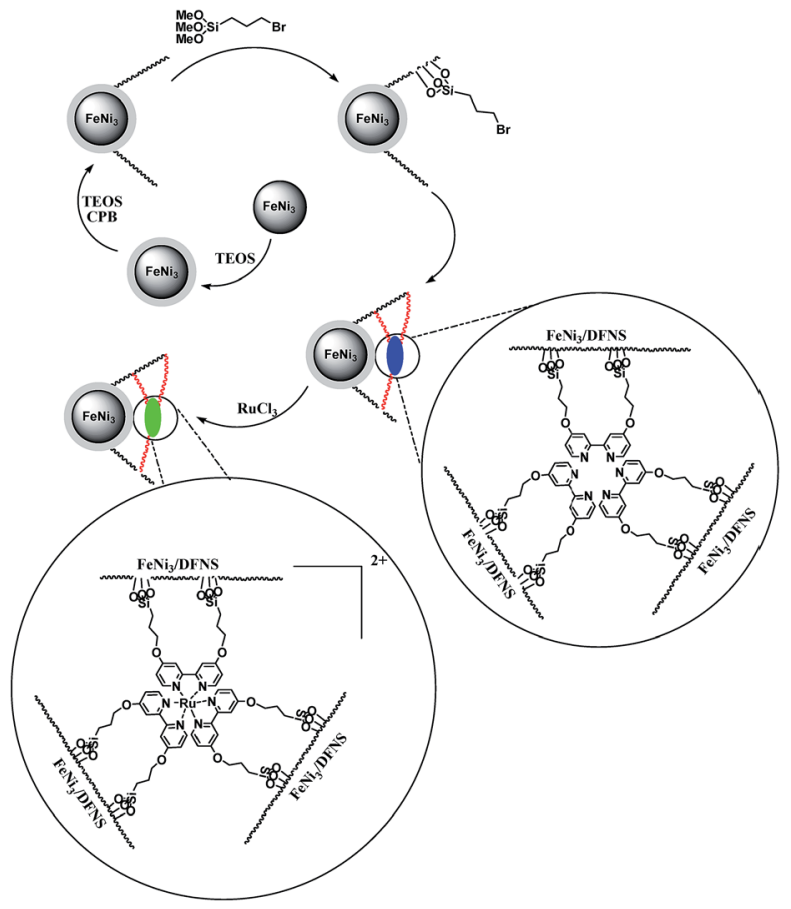

Scheme 3 The process of co-immobilization of $\left[\mathrm{Ru}(\mathrm{Bpy})_{3}\right]^{2+}$ on 3 bromopropyl trimethoxysilane functionalized $\mathrm{FeNi}_{3} / \mathrm{DFNS}$ nanoparticles.
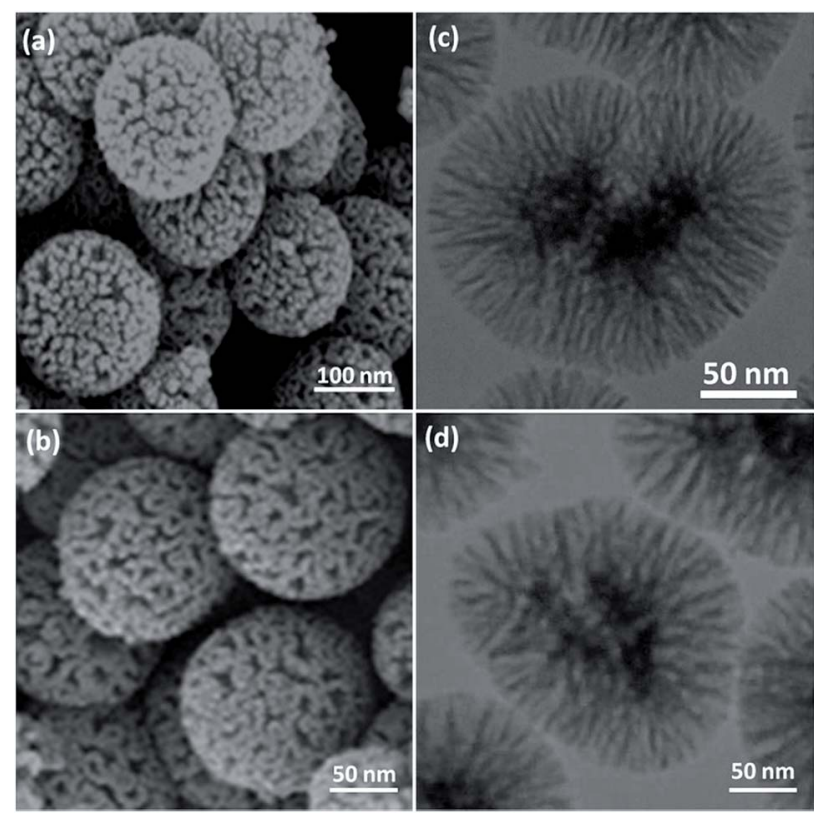

Fig. 1 FESEM images of $\mathrm{FeNi}_{3} / \mathrm{DFNS}$ MNPs (a) and $\mathrm{FeNi}_{3} / \mathrm{DFNS} /$ $\left[\mathrm{Ru}(\mathrm{Bpy})_{3}\right]^{2+} \mathrm{MNPs}(\mathrm{b}) ;$ TEM images of $\mathrm{FeNi}_{3} / \mathrm{DFNS} \mathrm{MNPs}$ (c) and $\mathrm{FeNi}_{3} /$ DFNS/[Ru(Bpy) $\left.)_{3}\right]^{2+}$ MNPs (d).

a core $\mathrm{FeNi}_{3}$ particle, a nonporous silica layer and silica fibres, and the samples comprise spheres of uniform size with diameters of $\sim 300 \mathrm{~nm}$ with a wrinkled radial structure. Scrutiny of TEM and FESEM images indicated that the $\mathrm{FeNi}_{3} / \mathrm{DFNS} /$ $\left[\mathrm{Ru}(\mathrm{Bpy})_{3}\right]^{2+}$ consists of dendrimeric fibers with thicknesses of
5-8 $\mathrm{nm}$ ordered in three dimensions to create walls, which can allow straightforward access to the large surface area available. From FESEM and TEM analyses of $\mathrm{FeNi}_{3} / \mathrm{DFNS} /\left[\mathrm{Ru}(\mathrm{Bpy})_{3}\right]^{2+}$ MNPs, it can be seen that this arrangement is not altered after changing the morphology of the MNPs (Fig. 1b and d). Fig. 2 demonstrates the TGA of $\mathrm{FeNi}_{3} / \mathrm{DFNS} /\left[\mathrm{Ru}(\mathrm{Bpy})_{3}\right]^{2+}$ MNPs. The removal of the solvent chemisorbed and physisorbed on the surface of the $\mathrm{FeNi}_{3} / \mathrm{DFNS} /\left[\mathrm{Ru}(\mathrm{Bpy})_{3}\right]^{2+}$ material led to weight loss. In addition, weight loss of almost $29.1 \mathrm{wt} \%$ in the range 250-450 ${ }^{\circ} \mathrm{C}$ was related to the organic group derivatives. The reduction in weight at this range of temperature can be rationalized as being due to oxidation of ruthenium(II) complexes. In fact, the residual mass after the decomposition of $\mathrm{FeNi}_{3}$ /DFNS/ $\left[\mathrm{Ru}(\mathrm{Bpy})_{3}\right]^{2+}$ MNPs is due to the vacated $\mathrm{FeNi}_{3} / \mathrm{DFNS}$ NPs.

The X-ray diffraction patterns for $\mathrm{FeNi}_{3}, \mathrm{FeNi}_{3} / \mathrm{DFNS}$, and $\mathrm{FeNi}_{3} / \mathrm{DFNS} /\left[\mathrm{Ru}(\mathrm{Bpy})_{3}\right]^{2+}$ MNPs are shown in Fig. 3. All spectra have in common the (111), (200), and (220) diffraction peaks in proper accord with the information in JCPDS card no. 19-0629 for the $\mathrm{FeNi}_{3}$ component of the samples (Fig. 3a). In addition to these iron oxide peaks, the XRD patterns of nanoparticles of the $\mathrm{FeNi}_{3} /$ DFNS core-shell contained a wide peak at low diffraction angle that related to amorphous silica (as can be seen in Fig. 3b). Fig. 3c shows an XRD pattern for the $\mathrm{FeNi}_{3} / \mathrm{DFNS} /$ $\left[\mathrm{Ru}(\mathrm{Bpy})_{3}\right]^{2+}$ MNPs that was unchanged from that of $\mathrm{FeNi}_{3} /$ DFNS.

The $\mathrm{FeNi}_{3} / \mathrm{DFNS} /\left[\mathrm{Ru}(\mathrm{Bpy})_{3}\right]^{2+}$ MNPs surface roughness was investigated by atomic force microscopy (AFM). Fig. 4 shows the topographic picture for $\mathrm{FeNi}_{3} / \mathrm{DFNS} /\left[\mathrm{Ru}(\mathrm{Bpy})_{3}\right]^{2+}$ MNPs. As can be observed in Fig. 4, the highest regions, indicated by the brighter yellowish white color, were enhanced by decreasing $\mathrm{T} /$ $\mathrm{W}$, suggesting an increase in the roughness of the catalyst surface.

The FTIR spectra demonstrate the presence of silanols, phosphate groups, and hydroxyl organic groups in both $\mathrm{FeNi}_{3} /$ DFNS MNPs (Fig. 5a) and $\mathrm{FeNi}_{3} / \mathrm{DFNS} /\left[\mathrm{Ru}(\mathrm{Bpy})_{3}\right]^{2+}$ MNPs (Fig. 5b). In the case of $\mathrm{FeNi}_{3} / \mathrm{DFNS}$ the wide absorption zones at 1099 and $3561 \mathrm{~cm}^{-1}$ are ascribed to $\mathrm{Si}-\mathrm{O}-\mathrm{Si}$ asymmetric stretching and $\mathrm{OH}$ respectively. Two peaks at 799 and $467 \mathrm{~cm}^{-1}$ are present in Fig. 5a, for $\mathrm{Si}-\mathrm{O}-\mathrm{Si}$ symmetrical stretching and bending, respectively. These peaks show the linkage of $\left[\mathrm{Ru}(\mathrm{Bpy})_{3}\right]^{2+}$ onto the surface of $\mathrm{FeNi}_{3} / \mathrm{DFNS}$. The composite $\mathrm{FeNi}_{3} / \mathrm{DFNS} /\left[\mathrm{Ru}(\mathrm{Bpy})_{3}\right]^{2+}$ shows bands at 1195, 799 and

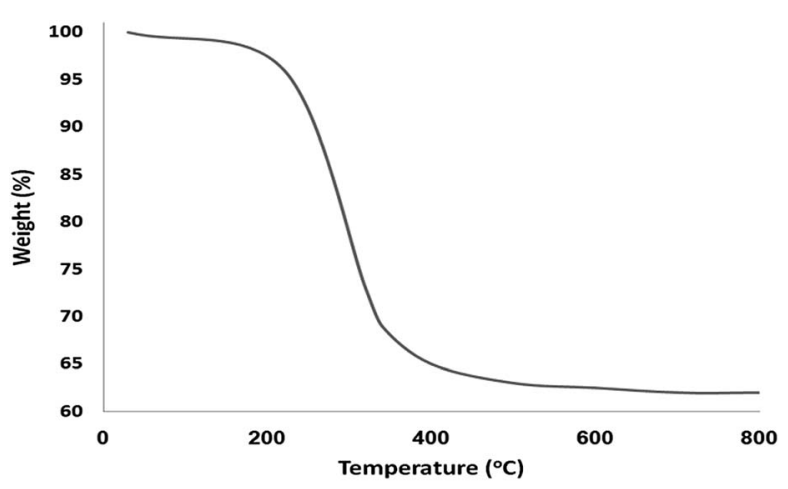

Fig. 2 TGA diagram of $\mathrm{FeNi}_{3} / \mathrm{DFNS} /\left[\mathrm{Ru}(\mathrm{Bpy})_{3}\right]^{2+} \mathrm{MNPs}$. 


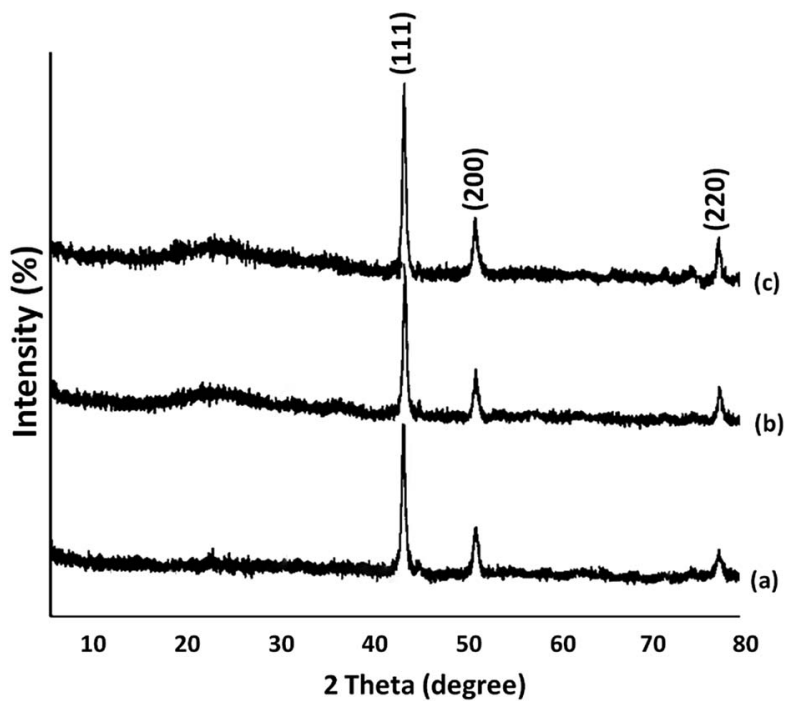

Fig. 3 XRD analysis of (a) $\mathrm{FeNi}_{3}$, (b) $\mathrm{FeNi}_{3} / \mathrm{DFNS}$, and (c) $\mathrm{FeNi}_{3} / \mathrm{DFNS} /$ $\left[\mathrm{Ru}(\mathrm{Bpy})_{3}\right]^{2+}$ MNPs.

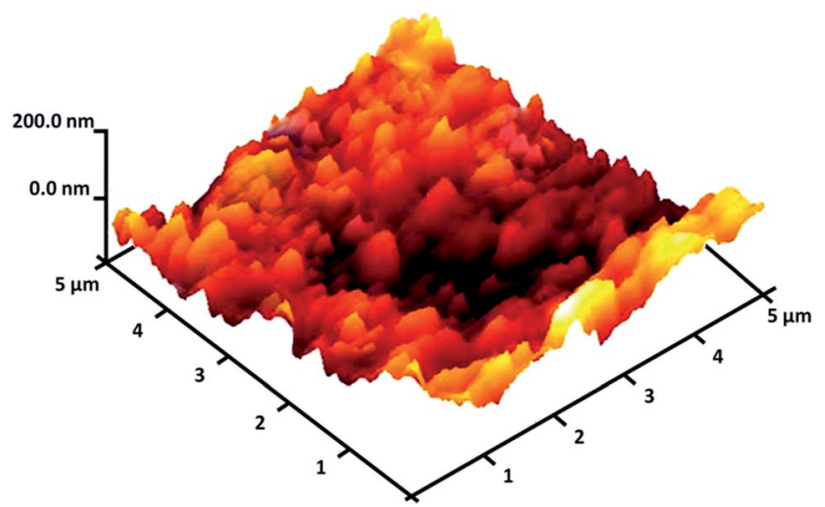

Fig. 4 Three-dimensional AFM image of $\mathrm{FeNi}_{3} / \mathrm{DFNS} /\left[\mathrm{Ru}(\mathrm{Bpy})_{3}\right]^{2+}$ MNPs.

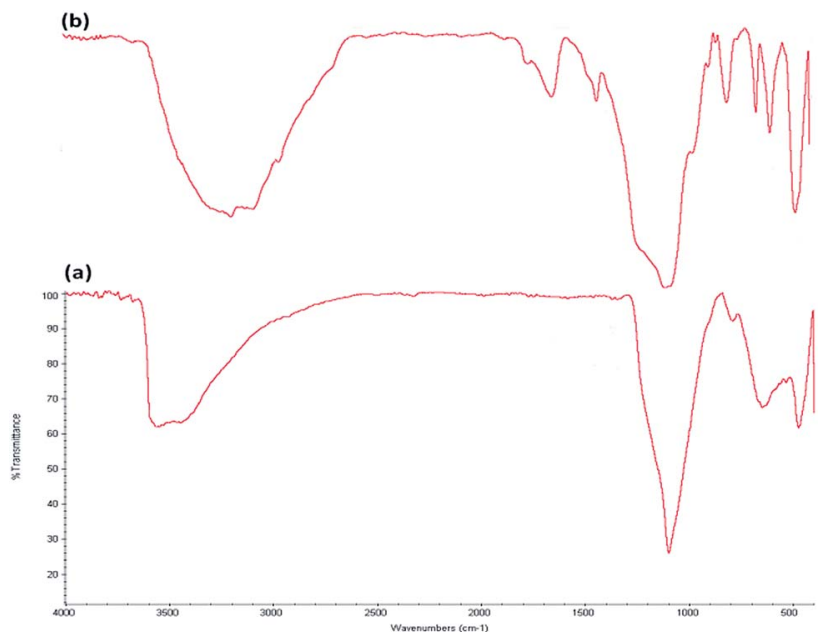

Fig. 5 FTIR spectra of (a) $\mathrm{FeNi}_{3} / \mathrm{DFNS}$ MNPs, and (b) $\mathrm{FeNi}_{3} / \mathrm{DFNS} /$ $\left[\mathrm{Ru}(\mathrm{Bpy})_{3}\right]^{2+}$ MNPs.
$467 \mathrm{~cm}^{-1}$. In the $3000-3550 \mathrm{~cm}^{-1}$ range, a strong and wide absorption band can be seen, which corresponds to $-\mathrm{OH}$ stretching vibrations. The peaks at 3120 and $2980 \mathrm{~cm}^{-1}$ that can be observed in Fig. 5b are due to stretching of the aromatic and aliphatic carbon-hydrogen bonds.

Vibrating sample magnetometry (VSM) was used for the determination of the nanoparticles' magnetic properties, with the magnetization curves of the obtained nanocomposite recorded at $300 \mathrm{~K}$. In Fig. 6, it is shown that no residual magnetism is detected, thus paramagnetic characteristics are exhibited by the nanocomposites. Saturation magnetization values of 53.8 and $24.1 \mathrm{emu} \mathrm{g}^{-1}$ were determined for $\mathrm{FeNi}_{3}$ and $\mathrm{FeNi}_{3} / \mathrm{DFNS} /\left[\mathrm{Ru}(\mathrm{Bpy})_{3}\right]^{2+}$ MNPs, respectively. Responsivity towards an external magnetic field and the ability for quick redispersion upon removal of the magnetic field are characteristic of paramagnetic nanocomposites with high magnetization values. The resultant nanocomposite exhibited good magnetic responsivity, suggesting potential application for targeting and separation.

The UV-vis spectra of neat complex and the supported $\mathrm{Ru}(\mathrm{II})$ catalysts are given in Fig. 7. The spectra of the supported ruthenium catalysts showed features similar to those of the neat complex. The bands at 210 and $325 \mathrm{~nm}$ can be attributed to the charge transfer transition of salen ligand. The band at $475 \mathrm{~nm}$ is due to ligand-to-metal charge transfer transition of $\mathrm{Ru}(\mathrm{II})$ salen complex. On immobilization of $\mathrm{Ru}$ salen complex, all the characteristic bands appeared in its spectra. The UV-vis spectra confirmed the immobilization of $\mathrm{Ru}$ salen complex on the supports.

The Brunauer-Emmett-Teller (BET) nitrogen physisorption analysis showed that the specific surface areas of $\mathrm{FeNi}_{3} / \mathrm{DFNS}$ and $\mathrm{FeNi}_{3} / \mathrm{DFNS} /\left[\mathrm{Ru}(\mathrm{Bpy})_{3}\right]^{2+}$ are around 721 , and $403 \mathrm{~m}^{2} \mathrm{~g}^{-1}$, respectively. The lower surface area of $\mathrm{FeNi}_{3} / \mathrm{DFNS} /\left[\mathrm{Ru}(\mathrm{Bpy})_{3}\right]^{2+}$ compared with $\mathrm{FeNi}_{3} /$ DFNS may be due to the $\left[\mathrm{Ru}(\mathrm{Bpy})_{3}\right]^{2+}$. Fig. 8 indicates the nitrogen adsorption as well as desorption isotherms of $\mathrm{FeNi}_{3} / \mathrm{DFNS}$ supported catalysts. The compound $\mathrm{FeNi}_{3} /$ DFNS shows a type IV isotherm and also a hysteresis loop of H1-type which suggests the presence of mesopores. The pore size estimated using the desorption section of the nitrogen

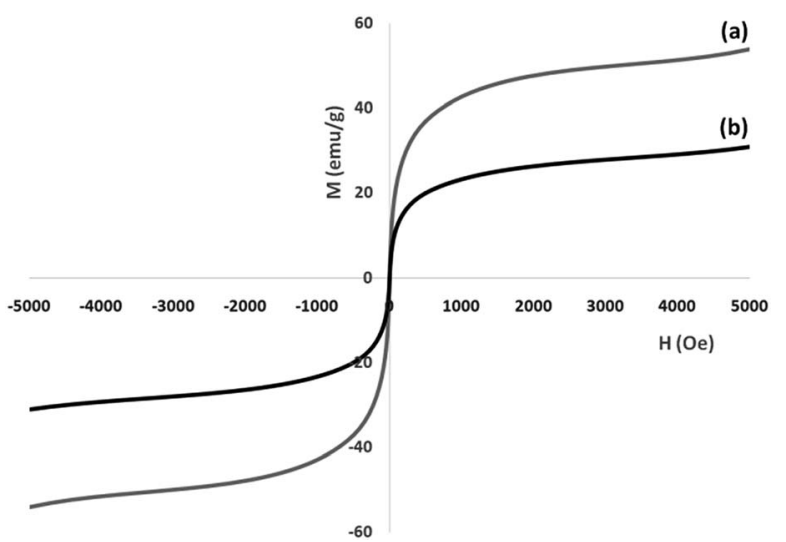

Fig. 6 Room-temperature magnetization curves of (a) $\mathrm{FeNi}_{3}$ and (b) $\mathrm{FeNi}_{3} / \mathrm{DFNS} /\left[\mathrm{Ru}(\mathrm{Bpy})_{3}\right]^{2+}$ MNPs. 


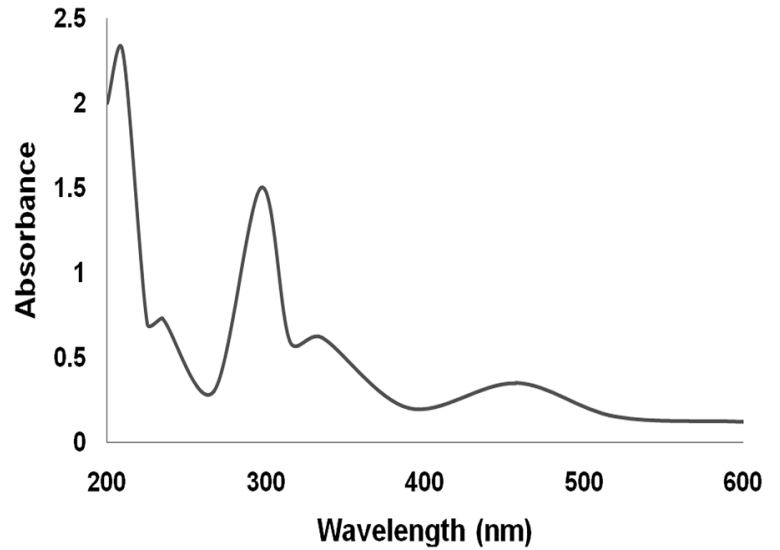

Fig. 7 UV-vis spectrum of the catalyst.
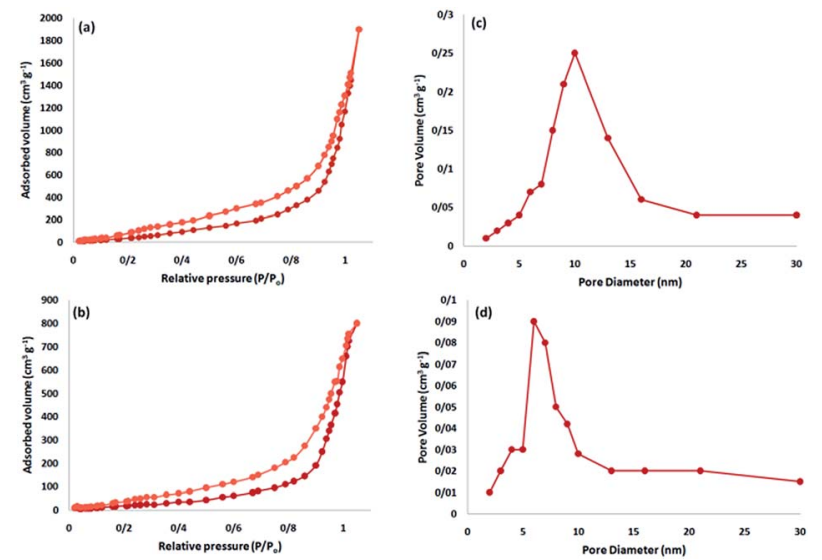

Fig. 8 Adsorption-desorption isotherms of the $\mathrm{FeNi}_{3} / \mathrm{DFNS} N \mathrm{NS}_{\mathrm{S}}(\mathrm{a})$, and $\mathrm{FeNi}_{3} / \mathrm{DFNS} /\left[\mathrm{Ru}(\mathrm{Bpy})_{3}\right]^{2+}(\mathrm{b}) ;$ and $\mathrm{BJH}$ pore size distributions of the $\mathrm{FeNi}_{3} /$ DFNS NPs (c), and FeNi $/$ /DFNS/[Ru(Bpy) $\left.{ }_{3}\right]^{2+}$ MNPs (d).

isotherm using the Barrett-Joyner-Halenda (BJH) method showed a narrow pore distribution peaking at around $11 \mathrm{~nm}$ for $\mathrm{FeNi}_{3} /$ DFNS (see Table 1). The large mesopore amount of $\mathrm{FeNi}_{3} /$ DFNS along with its high capacity can accomodate $\left[\mathrm{Ru}(\mathrm{Bpy})_{3}\right]^{2+}$, which possesses a comparatively big molecular size.

Different solvents were examined for the oxidation of phenol in the presence of $\mathrm{FeNi}_{3} / \mathrm{DFNS} /\left[\mathrm{Ru}(\mathrm{Bpy})_{3}\right]^{2+}$ MNPs, with the outcomes indicated in Fig. 9. Usual solvents such as ethyl acetate, water, isopropanol, and dichloromethane had no influence on the reaction. Methanol as a solvent produced a higher yield than did acetonitrile. It is important to note that though no reaction occurred in water, mixing water with acetonitrile caused a considerable enhancement in the

Table 1 Structural parameters of $\mathrm{FeNi}_{3} / \mathrm{DFNS}$ and $\mathrm{FeNi}_{3} / \mathrm{DFNS} /$ $\left[\mathrm{Ru}(\mathrm{Bpy})_{3}\right]^{2+} \mathrm{MNPS}$

\begin{tabular}{lllc}
\hline Catalyst & $S_{\text {BET }}\left(\mathrm{m}^{2} \mathrm{~g}^{-1}\right)$ & $V_{\mathrm{a}}\left(\mathrm{cm}^{3} \mathrm{~g}^{-1}\right)$ & $D_{\text {BJH }}(\mathrm{nm})$ \\
\hline $\mathrm{FeNi}_{3} / \mathrm{DFNS}$ & 721 & 3.7 & 11 \\
$\mathrm{FeNi}_{3} / \mathrm{DFNS} /\left[\mathrm{Ru}(\mathrm{Bpy})_{3}\right]^{2+}$ & 403 & 2.9 & 7
\end{tabular}

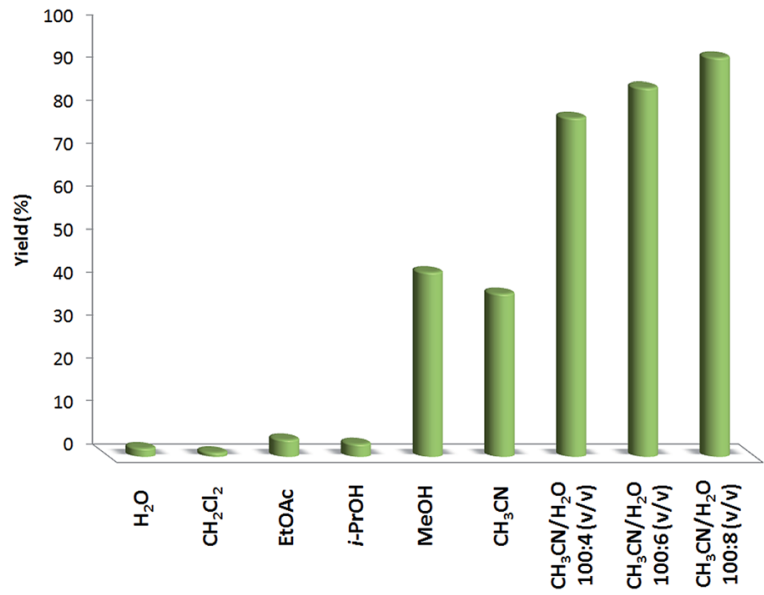

Fig. 9 Oxidation of phenol by $\mathrm{FeNi}_{3} / \mathrm{DFNS} /\left[\mathrm{Ru}(\mathrm{Bpy})_{3}\right]^{2+}$ MNPs in different solvents.

production of 1,4-benzoquinone. The yield of 1,4-benzoquinone obtained was close to $93 \%$ in a mixture of acetonitrile and water. No 1,2-benzoquinone or chlorophenol was made in this reaction (only different unidentified compounds). The product yield was enhanced from $79 \%$ to $93 \%$ when the volume of water was increased from 4 to $8 \mathrm{~mL}\left(\mathrm{CH}_{3} \mathrm{CN} / \mathrm{H}_{2} \mathrm{O}[100: 8(\mathrm{v} / \mathrm{v})]\right)$.

As can be observed in Table 2, the optimum temperature required for performing the reaction was investigated. After studying various temperatures, it was found that $40{ }^{\circ} \mathrm{C}$ was the most appropriate temperature for this reaction. Temperatures higher than around this did not increase production. Although increasing the temperature promoted the reaction, serious sidereactions occurred at over $40{ }^{\circ} \mathrm{C}$. Another factor that can be examined for the demonstrated reaction is the amount of $\mathrm{FeNi}_{3} /$ $\mathrm{DFNS} /\left[\mathrm{Ru}(\mathrm{Bpy})_{3}\right]^{2+}$ MNPs to be used. The reaction was

Table 2 Oxidation of phenol by $\mathrm{FeNi}_{3} / \mathrm{DFNS} /\left[\mathrm{Ru}(\mathrm{Bpy})_{3}\right]^{2+}$ MNPs for different temperatures, amounts of catalyst, $\mathrm{O}_{2}$ pressures, and reaction times

$\mathrm{O}_{2}$ pressure

Entry Temperature $\left({ }^{\circ} \mathrm{C}\right)$ Catalyst $(\mathrm{mg})$ Time (h) (MPa) Yield $^{a}(\%)$

\begin{tabular}{llllll}
\hline 1 & r.t. & 14 & 2 & 3.0 & - \\
2 & 30 & 14 & 2 & 3.0 & 71 \\
3 & 40 & 14 & 2 & 3.0 & 93 \\
4 & 50 & 14 & 2 & 3.0 & 93 \\
5 & 40 & 12 & 2 & 3.0 & 93 \\
6 & 40 & 10 & 2 & 3.0 & 93 \\
7 & 40 & 8 & 2 & 3.0 & 80 \\
8 & 40 & - & 2 & 3.0 & - \\
9 & 40 & 10 & 1 & 3.0 & 93 \\
10 & 40 & 10 & 0.5 & 3.0 & 39 \\
11 & 40 & 10 & 1 & 0.5 & 11 \\
12 & 40 & 10 & 1 & 1 & 52 \\
13 & 40 & 10 & 1 & 1.5 & 81 \\
14 & 40 & 10 & 1 & 2.0 & 93 \\
15 & 40 & 10 & 1 & 2.5 & 93 \\
16 & 40 & 10 & 1 & 3.5 & 91
\end{tabular}

${ }^{a}$ Isolated yield. 
performed at $2 \mathrm{~h}$ at the temperature of $40^{\circ} \mathrm{C}$, in the presence of catalyst $(8,10,12$, and $14 \mathrm{mg})$. As can be seen in Table 2 , in the absence of catalyst, no 1,4-benzoquinone was produced. Using different amounts of $\mathrm{FeNi}_{3} / \mathrm{DFNS} /\left[\mathrm{Ru}(\mathrm{Bpy})_{3}\right]^{2+}$ MNPs as catalyst led to variation in yield. The reaction using $8 \mathrm{mg}$ of catalyst produced an $80 \%$ yield after $2 \mathrm{~h}$ duration. Increasing the amount of catalyst to $10 \mathrm{mg}$ increased the yield of 1,4-benzoquinone to about $93 \%$. Amounts of $\mathrm{FeNi}_{3} / \mathrm{DFNS} /\left[\mathrm{Ru}(\mathrm{Bpy})_{3}\right]^{2+}$ MNPs higher than $10 \mathrm{mg}$ did not further increase the yield. Entries 6, 9 and 10 indicate the effects of time. The product yield increased on changing the reaction time from $0.5 \mathrm{~h}$ to $1 \mathrm{~h}$. In addition, Table 2 indicates the influences of oxygen pressure. The yield of 1,4-benzoquinones was highly enhanced when oxygen pressure was increased from 0.5 bar to 2.0 bar owing to the increased oxygen concentration in the reaction mixture. By increasing the oxygen pressure to 3.5 bar, the phenol concentration is diluted and the reaction activity decreased.

In order to study the performance of the catalyst, various control experiments were done; the data obtained are presented in Fig. 10. Firstly, the reaction was performed using $\mathrm{FeNi}_{3} /$ DFNS, and it was found that none of the favorable product was made in $1 \mathrm{~h}$ reaction time. In addition, when $\mathrm{FeNi}_{3} / \mathrm{DFNS} / \mathrm{Bpy}$ was utilized as the catalyst, a reaction could not be seen. The Bpy cannot catalyze the reaction under moderate reaction conditions. Following these negative results, we carried on the investigation to enhance the amount of product by adding the ruthenium(II). It is important to note that there is not a high variation between the yields obtained when the reaction was performed with $\mathrm{FeNi}_{3} / \mathrm{DFNS} /\left[\mathrm{Ru}(\mathrm{Bpy})_{3}\right]^{2+} \quad$ MNPs and $\left[\mathrm{Ru}(\mathrm{Bpy})_{3}\right]^{2+}$ catalyst, but $\left[\mathrm{Ru}(\mathrm{Bpy})_{3}\right]^{2+}$ is not reusable. These results prove that the reaction is basically catalyzed using $\left[\mathrm{Ru}(\mathrm{Bpy})_{3}\right]^{2+}$ functional groups within the nanostructure of $\mathrm{FeNi}_{3} /$ DFNS. The nano-sized particles increase the presented surface of the active catalyst, therefore increasing the contiguity between catalyst and reactants, mimicking homogeneous catalysts. Nanoparticles of $\mathrm{FeNi}_{3} / \mathrm{DFNS} /\left[\mathrm{Ru}(\mathrm{Bpy})_{3}\right]^{2+}$ were utilized in the subsequent studies due to their appropriate high selectivity, reactivity, and easy separation. In addition, the activity and selectivity of the nano-catalyst may be managed by

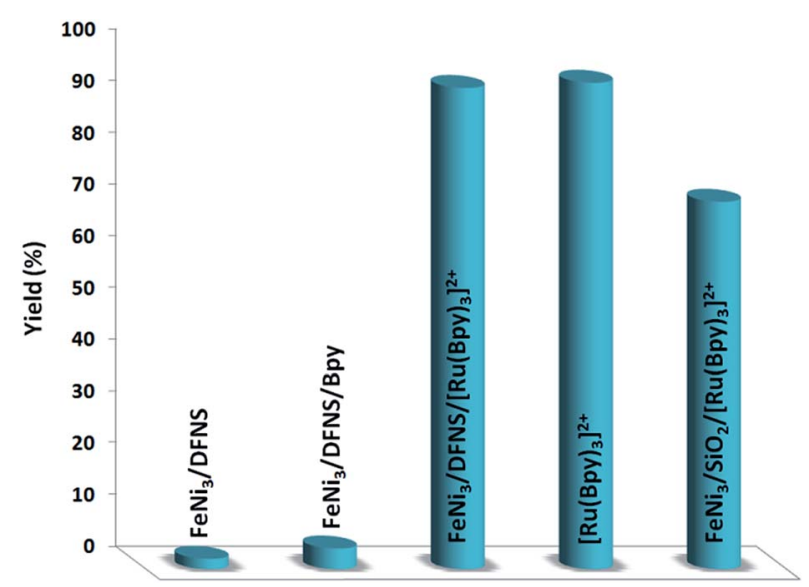

Fig. 10 Oxidation of phenol by different $\mathrm{FeNi}_{3} /$ DFNS nanoparticles. tailoring chemical and physical characteristics such as composition, shape, and size, as well as morphology. To investigate the exact effect of the presence of DFNS in the catalyst, the MNPs of $\mathrm{FeNi}_{3} / \mathrm{DFNS} /\left[\mathrm{Ru}(\mathrm{Bpy})_{3}\right]^{2+}$ were compared with $\mathrm{FeNi}_{3} / \mathrm{SiO}_{2} /\left[\mathrm{Ru}(\mathrm{Bpy})_{3}\right]^{2+}$ MNPs, which possess identical compositions but distinct structures. When $\mathrm{FeNi}_{3} / \mathrm{SiO}_{2} /$ $\left[\mathrm{Ru}(\mathrm{Bpy})_{3}\right]^{2+}$ was utilized as the catalyst, the yield of the desired product was near to the mean value; however, the product for $\mathrm{FeNi}_{3} / \mathrm{DFNS} /\left[\mathrm{Ru}(\mathrm{Bpy})_{3}\right]^{2+}$ was better.

Different phenols were tested, and the outcomes are presented in Table 3. Generally, the reactivity of phenols depended on the number of alkyl groups in the benzene ring. Full conversion of 2,3,5,6-tetramethylphenol to yield $95 \%$ tetramethyl-1,4-benzoquinone was obtained at a temperature of $25{ }^{\circ} \mathrm{C}$ and a pressure of 2.0 bar for 1 hour. When 3,5-dimethylphenol was utilized, $90 \%$ production of 2,6-dimethyl-1,4benzoquinone was achieved. A yield of $85 \%$ was obtained for 2,6-dimethylphenol under identical conditions. For 2,3,6-trimethylphenol, 92\% production of trimethyl-1,4-benzoquinone was achieved. A similar outcome (94\% yield) was determined for 2,3,5-trimethylphenol under identical conditions. A yield of 91\% tert-butyl-1,4-benzoquinone were found for 2-tert-butylphenol. Under the same conditions, $89 \%$ of 2-methoxyphenol was converted to methyl-1,4-benzoquinone. In experiments using phenols with electron-withdrawing groups, such as halogen, no reaction was observed even after prolonged time.

The effect of various solvents for production of vitamin K3 was investigated. For polar protic solvents, like water, ethanol, methanol and isopropanol, none of the desired product was formed. Hence, the production of the cross-coupling is comparatively poor for polar aprotic solvents like $\mathrm{CHCl}_{3}, \mathrm{DMF}$, DMSO and $\mathrm{CH}_{2} \mathrm{Cl}_{2}$ as well as EtOAc. In the present paper, it was determined that heating with acetonitrile is very effective compared with utilizing organic solvents and produces green conditions for vitamin K3 production (see Table 4).

In this paper, the crucial role of temperature was investigated for vitamin $\mathrm{K} 3$ production in the presence of the MNPs of $\mathrm{FeNi}_{3} / \mathrm{DFNS} /\left[\mathrm{Ru}(\mathrm{Bpy})_{3}\right]^{2+}$ as catalyst. The most appropriate temperature in the case of this reaction was obtained by heating under reflux to improve the performance of the reaction. This indicated the catalytic activity is sensitive to the temperature of reaction. The amount of catalyst is a significant parameter in the considered reaction to obtain vitamin K3. No yield was obtained in the absence of the catalyst. When $0.2-0.8 \mathrm{mg}$ of $\mathrm{FeNi}_{3} /$ $\mathrm{DFNS} /\left[\mathrm{Ru}(\mathrm{Bpy})_{3}\right]^{2+}$ MNPs was used in this reaction, production of vitamin K3 was achieved under mild conditions. The best result was obtained when the model reaction was performed in the presence of $1 \mathrm{mg}$ of $\mathrm{FeNi}_{3} / \mathrm{DFNS} /\left[\mathrm{Ru}(\mathrm{Bpy})_{3}\right]^{2+}$ MNPs. Further increasing the amount of catalyst did not enhance the yield in the model reaction (Fig. 11). Under the optimized conditions, GC (gas chromatography) was used to analyse the minimum reaction time necessary in the presence of $\mathrm{FeNi}_{3} / \mathrm{DFNS} /$ $\left[\mathrm{Ru}(\mathrm{Bpy})_{3}\right]^{2+}$ MNPs $(1 \mathrm{mg}$, showing that good yields of vitamin K3 may be obtained at $8 \mathrm{~h}$ Fig. 12).

We consider that the following hypothesis based on phenol is reasonable (Fig. 13): $\mathrm{FeNi}_{3} / \mathrm{DFNS} /\left[\mathrm{Ru}(\mathrm{Bpy})_{3}\right]^{2+}$ is oxidized by dioxygen as ruthenium(II), which oxidizes phenols to produce 
Table 3 The results for aerobic oxidation of various phenols into 1,4benzoquinones $^{a}$
Substrate<smiles>Cc1cc(C)c(C)c(O)c1C</smiles><smiles>Cc1ccc(C)c(O)c1C</smiles><smiles>Cc1cc(C)c(C)c(O)c1</smiles><smiles>Cc1cc(C)cc(O)c1</smiles><smiles>Cc1cccc(C)c1O</smiles><smiles>Cc1cccc(O)c1</smiles><smiles>Cc1ccccc1O</smiles><smiles>Oc1ccccc1C(Br)(Br)Br</smiles>

8

9<smiles>COc1ccccc1O</smiles>

10<smiles>Oc1ccccc1F</smiles>

11<smiles>Oc1ccccc1Cl</smiles>

Product

Yield (\%)<smiles>CC1=C(C)C(=O)C(C)=C(C)C1=O</smiles>

95<smiles>CC1=CC(=O)C(C)=C(C)C1=O</smiles>

92<smiles>CC1=CC(=O)C(C)=C(C)C1=O</smiles><smiles>CC1=CC(=O)C=C(C)C1=O</smiles><smiles>CC1=CC(=O)C=C(C)C1=O</smiles><smiles>CC1=CC(=O)C=CC1=O</smiles><smiles>CC1=CC(=O)C=CC1=O</smiles><smiles>CC(C)(C)C1=CC(=O)C=CC1=O</smiles><smiles>COC1=CC(=O)C=CC1=O</smiles><smiles>O=C1C=CC(=O)C(F)=C1</smiles><smiles>O=C1C=CC(=O)C(Cl)=C1</smiles>

91

89

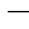

Table 3 (Contd.)

\begin{tabular}{llll}
\hline Entry & Substrate & Product & Yield (\%) \\
\hline
\end{tabular}

12<smiles>Oc1ccccc1Br</smiles><smiles>O=C1C=CC(=O)C(Br)=C1</smiles>

13<smiles>Oc1ccccc1I</smiles><smiles>O=C1C=CC(=O)C(I)=C1</smiles>

${ }^{a}$ Isolated yield.
Table 4 Synthesis of vitamin $\mathrm{K} 3$ by $\mathrm{FeNi}_{3} / \mathrm{DFNS} /\left[\mathrm{Ru}(\mathrm{Bpy})_{3}\right]^{2+}$ MNPs in different solvents ${ }^{a}$
90

85

15

\begin{tabular}{lll}
\hline Entry & Solvent & Yield $^{b}(\%)$ \\
\hline 1 & $\mathrm{H}_{2} \mathrm{O}$ & - \\
2 & $\mathrm{MeOH}$ & - \\
3 & $\mathrm{EtOH}$ & - \\
4 & i-PrOH & - \\
5 & Dioxane & - \\
6 & $n$-Hexane & - \\
7 & THF & 17 \\
8 & Toluene & 61 \\
9 & $\mathrm{CH}_{2} \mathrm{Cl}_{2}$ & 35 \\
10 & $\mathrm{CHCl}_{3}$ & 38 \\
11 & DMSO $_{13}$ & 43 \\
12 & $\mathrm{CH}_{3} \mathrm{CN}$ & 93 \\
13 & EtOAc & 23 \\
14 & DMF & 67 \\
15 & Solvent-free & -
\end{tabular}

${ }^{a}$ Reaction conditions: 2-methyl naphthalene $(10 \mathrm{mmol})$, glacial acetic acid $(2 \mathrm{~mL}), \mathrm{H}_{2} \mathrm{O}_{2}(0.1 \mathrm{~mL})$ and $\mathrm{FeNi}_{3} / \mathrm{DFNS} /\left[\mathrm{Ru}(\mathrm{Bpy})_{3}\right]^{2+}$ MNPs $(2 \mathrm{mg})$ were stirred together while being heated under reflux in solvent $(20$ $\mathrm{mL}$ ) for 10 hours. ${ }^{b}$ Isolated yields.

phenoxy radicals; the produced radical intermediates react with $\mathrm{O}_{2}$ to form 1,4-benzoquinone and $\mathrm{H}_{2} \mathrm{O}$. Since phenol and $o$ mono-alkyl substituted phenols are inert, strong conditions such as higher temperature are required for the activation of the $\mathrm{C}-\mathrm{H}$ bond in the para-position of these phenols. Because the radical intermediates of phenol and inert $o$-alkyl phenols produced during reaction are really active, a high pressure of dioxygen is necessary to keep dioxygen at a higher concentration in solution, which scavenges the intermediates to form the final products. That too high a pressure of dioxygen gives no clear improvement is evidence for this.

The reusability of a catalyst is a significant property in the case of green chemistry. Hence, the reusability of MNPs of $\mathrm{FeNi}_{3} / \mathrm{DFNS} /\left[\mathrm{Ru}(\mathrm{Bpy})_{3}\right]^{2+}$ was investigated under optimal conditions for the aerobic oxidation of phenol. After performing 


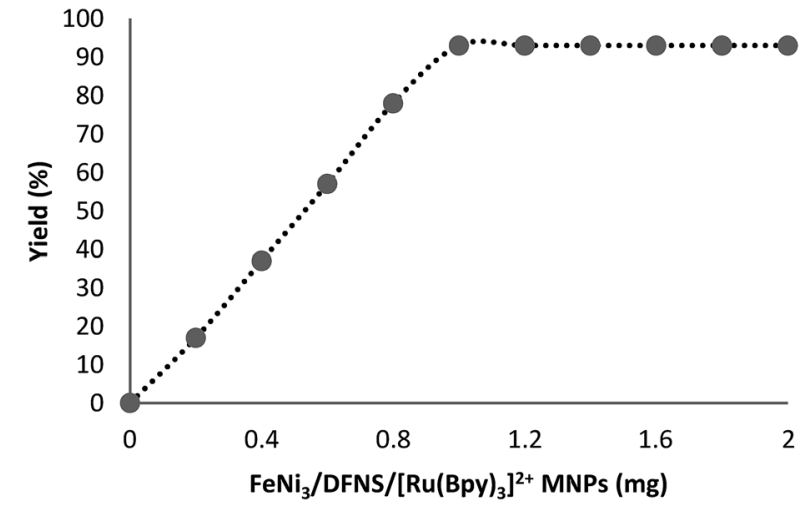

Fig. 11 Effect of increasing amount of $\mathrm{FeNi}_{3} / \mathrm{DFNS} /\left[\mathrm{Ru}(\mathrm{Bpy})_{3}\right]^{2+} \mathrm{MNPS}$ on the preparation of vitamin $\mathrm{K} 3$.

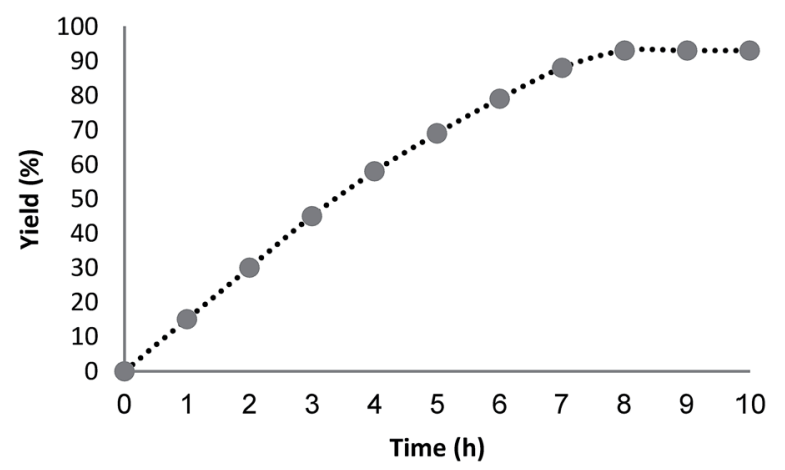

Fig. 12 Effect of time on yield of vitamin K3.

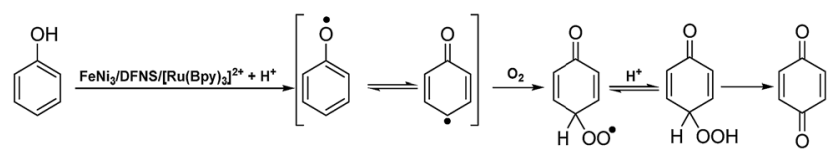

Fig. 13 Aerobic oxidation of phenol into 1,4-benzoquinone over $\mathrm{FeNi}_{3} / \mathrm{DFNS} /\left[\mathrm{Ru}(\mathrm{Bpy})_{3}\right]^{2+}$.

the reaction, the solid MNPs of $\mathrm{FeNi}_{3} / \mathrm{DFNS} /\left[\mathrm{Ru}(\mathrm{Bpy})_{3}\right]^{2+}$ were directly separated from the liquid reaction zone, magnetically, as when the reaction mixture is placed near a magnet, the solid readily separates from the solution in a few seconds. After cleaning with solvent, the catalyst can quickly be reused. Fig. 14 indicates the results of reusing the catalyst for 10 consecutive runs. The yield of product obtained was $90 \%$ at the tenth run, which means only a $3 \%$ drop in performance was seen in comparison with the fresh catalyst (93\%). In addition, the amount of ruthenium leached into the solution for oxidation of phenol after each run was evaluated using ICP. The catalyst indicated very little leaching in each run: $0.6 \%$ metal leaching was discovered after the tenth run, so showing the durability of the catalyst under the reaction conditions, as illustrated in Fig. 15.

In addition, two studies were performed to clarify the heterogeneous nature of the catalyst. Firstly, we did a hot

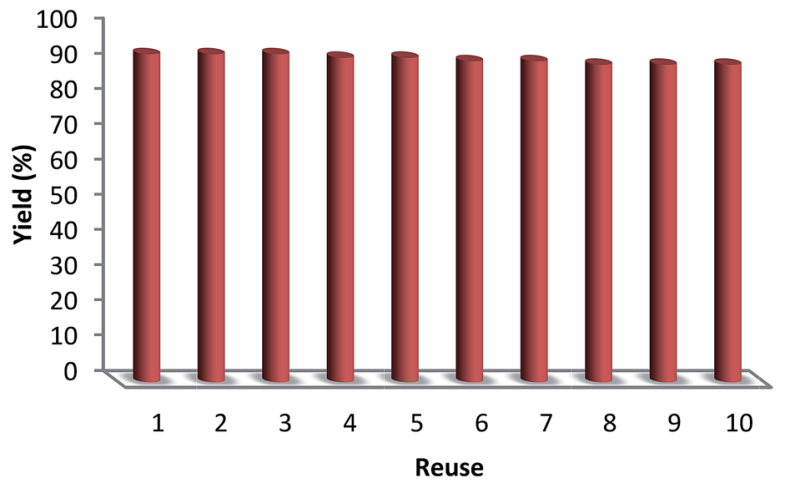

Fig. 14 The reusability of catalysts for oxidation of phenol.

filtration experiment on the oxidation of phenol under optimum conditions and determined that around $39 \%$ of the catalyst was magnetically removed in situ after $30 \mathrm{~min}$ of reaction. In addition, the reactants were able to tolerate more reaction. The outcome was that, after the heterogeneous catalyst had been removed, the free catalyst remaining was feebly active, and a conversion of about $42 \%$ was obtained after 1 hour of the oxidation of phenol. This proved that the catalyst worked heterogeneously during the reaction and showed just slight leaching. Secondly, to confirm the heterogeneous form of the catalyst, mercury poisoning was additionally performed. Mercury(0) was used directly or synthesized in situ, and dramatically deactivated the metal catalyst on the active surface, so reducing the catalytic activity. The experiment conducted is proof of the heterogeneous nature of the catalyst. This test was performed with the aforesaid model reaction under optimal conditions. After $30 \mathrm{~min}$ of the reaction, about 300 molar mercury was released into the reaction mixture. The reaction mixture was stirred for more than 1 hour, during which period no further conversion was seen. The kinetic scheme of the reaction in the presence of $\mathrm{Hg}(0)$ is shown in Fig. 16. The negative outcomes obtained from both of the heterogeneity experiments $(\mathrm{Hg}(0)$ poisoning as well as hot filtration) suggested that the solid catalyst is really heterogeneous and no measurable ruthenium is leached upon oxidation of phenol.

Finally, we checked whether the structure of the recovered catalyst was maintained after 10 runs for the catalytic oxidation

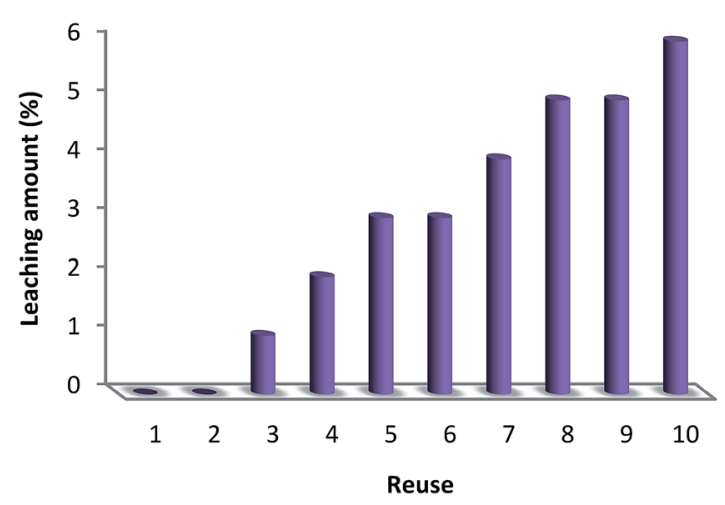

Fig. 15 Recyclability of the catalyst for oxidation of phenol. 


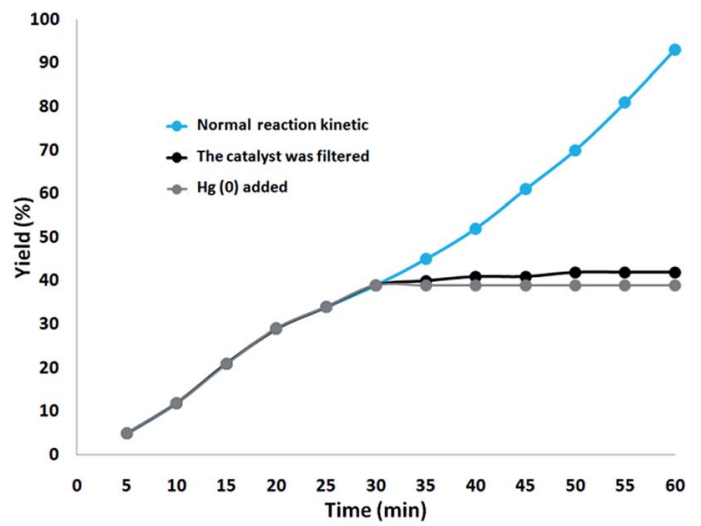

Fig. 16 Reaction kinetics, $\mathrm{Hg}(0)$ poisoning, and hot filtration studies for oxidation of phenol.

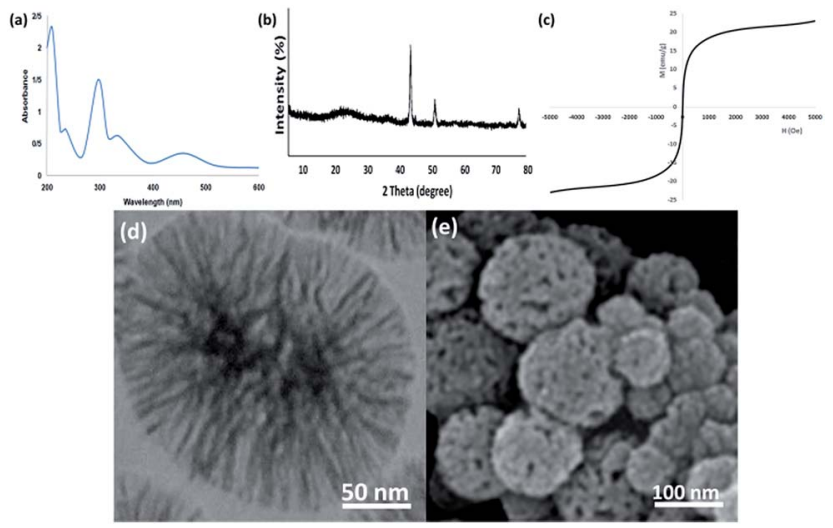

Fig. 17 (a) EDX, (b) XRD, (c) VSM, (d) TEM, and (e) FESEM images of the recovered $\mathrm{FeNi}_{3} / \mathrm{DFNS} /\left[\mathrm{Ru}(\mathrm{Bpy})_{3}\right]^{2+}$ MNPs after the 10th run for oxidation of phenol.

of phenol under the determined optimum conditions using EDX, XRD, VSM, TEM, and FESEM (Fig. 17). The UV-vis spectrum for the retrieved catalyst retained the attendant parameters, so vouching for the integrity of the catalyst within the reactions, as observed in Fig. 17a. As seen in Fig. 17b, the XRD pattern of the recovered catalyst proved that the catalyst structure remained totally intact during recycling. The catalyst sticks to the applied magnetic zone and can be easily prepared to be used again in the reaction mixture just like the fresh catalyst (Fig. 17c). It is worth noting that the nanocatalyst did not show any morphological changes in the TEM and FESEM images obtained from the recovered catalyst (Fig. 17d and e).

\section{Conclusions}

A very impressive hybrid catalyst was produced based on heterogeneous materials consisting of essentially different catalytic kinds. The hybrid catalyst was finely specified, and a complex formed by co-immobilization of ruthenium(II) on the $\mathrm{FeNi}_{3} /$ DFNS fibers was demonstrated. $\mathrm{FeNi}_{3} / \mathrm{DFNS} /\left[\mathrm{Ru}(\mathrm{Bpy})_{3}\right]^{2+}$ showed appropriate catalytic activity in the case of phenol oxidation for synthesis of 1,4-benzoquinone derivatives as well as for eco-friendly production of vitamin K3. This green approach has some noteworthy eco-friendly properties, such as the simplicity of catalyst reclamation from the reaction mixture using a magnet, the use of molecular $\mathrm{O}_{2}$ as a non-toxic oxidant, and the synthesis of water as a by-product. Bio-catalysts (heterogeneous form) may improve the performance of the catalytic method in green organic synthesis, particularly accompanied by environmentally friendly solvents.

\section{Conflicts of interest}

There are no conflicts to declare.

\section{Acknowledgements}

This work was funded by the Zhejiang Provincial Natural Science Foundation of China (Grant No. LQ15E080007), the Jinhua Science and Technology Development Foundation of China (Grant No. 2018-3-002), and the Qianjiang College Natural Science Foundation of China (2019QJJL03).

\section{Notes and references}

1 H. Shekari, M. Sayadi, M. Rezaei and A. Allahresani, Surf. Interfaces, 2017, 8, 199-205.

2 A. Maity and V. Polshettiwar, ChemSusChem, 2017, 10, 38663913.

3 S. M. Sadeghzadeh, RSC Adv., 2015, 5, 68947-68952.

4 U. Patil, A. Fihri, A. H. Emwas and V. Polshettiwar, Chem. Sci., 2012, 3, 2224-2229.

5 V. Polshettiwar, J. ThivolleCazat, M. Taoufik, F. Stoffelbach, S. Norsic and J. M. Basset, Angew. Chem., Int. Ed., 2011, 50, 2747-2751.

6 A. Fihri, D. Cha, M. Bouhrara, N. Almana and V. Polshettiwar, ChemSusChem, 2012, 5, 85-89.

7 A. Fihri, M. Bouhrara, U. Patil, D. Cha, Y. Saih and V. Polshettiwar, ACS Catal., 2012, 2, 1425-1431.

8 C. Chao, Y. F. Zhao, H. J. Guan, G. X. Liu, Z. G. Hu and B. Zhang, Environ. Eng. Sci., 2017, 34, 762-770.

9 J. Su, J. J. Fu, Q. Wang, C. Silva and A. Cavaco-Paulo, Crit. Rev. Biotechnol., 2018, 38, 294-307.

10 D. M. Mate and M. Alcalde, Biotechnol. Adv., 2015, 33, 25-40. 11 J. R. Jeon and Y. S. Chang, Trends Biotechnol., 2013, 31, 335341.

12 S. M. Sadeghzadeh, R. Zhiani and S. Emrani, New J. Chem., 2018, 42, 988-994.

13 A. Das and S. S. Stahl, Angew. Chem., 2017, 56, 8892-8897.

14 K. Engström, E. V. Johnston, O. Verho, K. P. J. Gustafson, M. Shakeri, C. W. Tai and J. E. Bäckvall, Angew. Chem., 2013, 125, 14256-14260.

15 B. S. Murray, M. V. Babak, C. G. Hartinger and P. J. Dyson, Coord. Chem. Rev., 2016, 306, 86-114.

16 C. S. Allardyce and P. J. Dyson, Dalton Trans., 2016, 45, 32013209.

17 M. Hanif and C. G. Hartinger, Future Med. Chem., 2018, 10, 615-617. 
18 A. A. Nazarov, C. G. Hartinger and P. J. Dyson, J. Organomet. Chem., 2014, 751, 251-260.

19 J. M. Gichumbi and H. B. Friedrich, J. Organomet. Chem., 2018, 866, 123-143.

20 A. D. Liang, J. Serrano-Plana, R. L. Peterson and T. R. Ward, Acc. Chem. Res., 2019, 52, 585-595.

21 R. Matheu, M. Z. Ertem, C. Gimbert-Surinach, X. Sala and A. Llobet, Chem. Rev., 2019, 119, 3453-3471.

22 P. Thangavel, B. Viswanath and S. Kim, Int. J. Nanomed., 2017, 12, 2749-2758.

23 J. Suriboot, H. S. Bazzi and D. E. Bergbreiter, Polymers, 2016, 8, 140.

24 F.-A. Khan and G. Süss-Fink, Eur. J. Inorg. Chem., 2012, 727732.

25 L. Wu, Y.-M. He and Q.-H. Fan, Adv. Synth. Catal., 2011, 353, 2915-2919.

26 L. Rosado Piquer, E. Jiménez Romero, Y. Lan, W. Wernsdorfer, G. Aromí and E. C. Sañudo, Inorg. Chem. Front., 2017, 4, 595-603.

27 R. J. Holmberg, A.-J. Hutchings, F. Habib, I. Korobkov, J. C. Scaiano and M. Murugesu, Inorg. Chem., 2013, 52, 14411-14418.

28 W. Bonrath and T. Netscher, Appl. Catal., A, 2005, 280, 55-73. 29 W. Bonrath, M. Eggersdorfer and T. Netscher, Catal. Today, 2007, 121, 45-57.

30 N. N. Trukhan, A. Yu. Derevyankin, A. N. Shmakov, E. A. Paukshtis, O. A. Kholdeeva and V. N. Romannikov, Microporous Mesoporous Mater., 2001, 44-45, 603-608.
31 N. N. Trukhan, V. N. Romannikov, E. A. Paukshtis, A. N. Shmakov and O. A. Kholdeeva, J. Catal., 2001, 202, 110-117.

32 O. A. Kholdeeva, N. N. Trukhan, M. P. Vanina, V. N. Romannikov, V. N. Parmon, J. Mrowiec-Bialon and A. B. Jarzebski, Catal. Today, 2002, 75, 203-209.

33 H. Xin, L. Hu, J. Yu, W. Sun and Z. An, Catal. Commun., 2017, 93, 1-4.

34 L. Hu, J. Yu, H. Xin and Z. An, ChemistrySelect, 2017, 2, 949952.

35 S. Urus, M. Keles and O. Serindag, J. Inorg. Organomet. Polym., 2010, 20, 152-160.

36 S. Urus, M. Keles and O. Serindag, Phosphorus, Sulfur Silicon Relat. Elem., 2010, 185, 1416-1424.

37 J. Kowalski, J. Płoszynska and A. Sobkowiak, Catal. Commun., 2003, 4, 603-608.

38 E. Shimanskaya, V. Doluda, M. Sulman, V. Matveeva and E. Sulman, Chem. Eng. J., 2014, 238, 206-209.

39 D. Chadar, M. Camilles, R. Patil, A. Khan, T. Weyhermüller and S. Salunke-Gawali, J. Mol. Struct., 2015, 1086, 179-189.

40 O. A. Anunziata, A. R. Beltramone and J. Cussa, Appl. Catal., A, 2004, 270, 77-85.

41 M. Florea, R. S. Marin, F. M. Palasanu, F. Neatu and V. I. Pârvulescu, Catal. Today, 2015, 254, 29-35.

42 R. Zhiani, S. M. Saadati, M. Zahedifar and S. M. Sadeghzadeh, Catal. Lett., 2018, 148, 2487-2500. 